Proc. Indian Acad. Sci. (Earth Planet. Sci.), Vol. 105, No. 1, March 1996, pp. 3139.

$\dot{c}$ Printed in India.

\title{
Fluxes of heat and momentum over sea surface during the passage of a depression in the north Bay of Bengal
}

\author{
S SIVARAMAKRISHNAN, M N PATIL and K G VERNEKAR \\ Indian Institute of Tropical Meteorology, Pune 411008 , India
}

\begin{abstract}
Time variation of surface fluxes of heat, moisture and momentum over a sea station $\left(20^{\prime} \mathrm{N}, 89^{\circ} \mathrm{E}\right)$ in the north Bay of Bengal has been computed by profile method for the period 18th - 25th August 1990 using meteorological data of MONTBLEX-90 from ORV Sagarkanya. The fluxes showed synoptic and diurnal variations which are marked during depression (20th - 21st August) compared to their variation prior to and after this period. Variations of heat and water vapour fluxes were in phase. Night time fluxes are relatively high compared to day time. Average momentum transfer during depression was two to three times large. Variations in Bowen ratio were relatively large during day time. During depression, it varied between 0.2 in day time and about 0.3 at night and in the undisturbed period between -0.1 and 0.2 during day time and 0.2 and 0.25 at night. The study shows that the assumption $C_{D}=C_{H}=C_{E}$ of the exchange coefficients normally used in estimating the fluxes by the bulk aerodynamic method is not appropriate because $C_{H} / C_{D} \approx 2, C_{E} / C_{D} \approx 1.5$ and $C_{H} / C_{E} \approx 1.4$.
\end{abstract}

Keywords. Flux; sea surface; depression; exchange coefficient; Bowen ratio; monsoon.

\section{Introduction}

Study of surface fluxes during a monsoon disturbance in the summer monsoon in the Indian subcontinent is of interest to both micro- and meso-scale meteorologists. In this paper our objective is to estimate and study the variation of the fluxes of sensible and latent heat, water vapour and momentum for the period 18 th -25 th August 1990 from the data collected during observations carried out onboard ORV Sagarkanya in the course of the Monsoon Trough Boundary Layer Experiment (MONTBLEX). During August 20th - 21st, a depression passed over the station. The vessel was moored at a sea station $\left(20^{\circ} \mathrm{N}, 89^{\circ} \mathrm{E}\right)$ and 3 -hourly observations were recorded by the National Institute of Oceanography, Goa, and the data provided to us for analysis.

\section{Instrumentation}

Surface meteorological observations on wind, temperature and atmospheric pressure were obtained using a wind vane and anemometer (electrical type) installed at $22.6 \mathrm{~m}$ above sea level on the radar deck of the ship. Dry and wet bulb temperatures were measured at the deck level $(9 \mathrm{~m}$ above msl) using an Assman type psychrometer. $A$ bucket thermometer was used to measure the sea surface temperature. In addition the cloud amount and type were observed. 


\section{Method of analysis}

The profile technique has been used to estimate the surface fluxes from wind and temperature data. The temperature difference and measurement of wind speed at only one height combined with roughness length (assumed) over sea surface have been used as input to compute Businger's similarity functions. Numerical iteration procedure is used to compute the friction velocity $u_{*}$ and temperature scale $\theta_{*}$ for $L=\infty, L$ being the Monin-Obukhov length. Details of the profile method and iteration procedure are found in Berkowicz and Prahm (1982). This method is computationally quick and in practical applications needs only a very few steps to achieve the required accuracy. Moreover, wind speed and temperature need not be given at the same height as in other formulations of the profile method (Businger et al 1971; Binkowski 1975; Louis 1979; Blanc 1982). It is argued (Berkowicz and Prahm 1982) that the error arising from the uncertainty in the determination of the roughness length $Z_{o}$ will be smaller than the error resulting from measurements of wind speed differences when only one speed measured at a height $Z$ such that $Z \gg Z_{o}$ is used to estimate the fluxes. A wide range of values for $Z_{o}$ has been reported in the literature: Counihan (1975) has summarised $Z_{o}$ for the adiabatic atmospheric boundary layer over different terrain types. Based on this we assume a value of $Z_{o}=2 \mathrm{~cm}$ over sea which seems plausible in disturbed weather.

\section{Results and discussion}

\subsection{Meteorological conditions}

Figures 1(a)-(d) depict the variation of sea surface temperature, surface pressure, wind speed and cloud amount respectively during August 18th - 25th, 1990. The maximum SST was observed around 1430-1730 hrs and minimum around midnight to early morning during August 18th -24 th. The minimum pressure was mostly observed at $1730 \mathrm{hrs}$ while the maximum was around $1130-1430$ and around $2330 \mathrm{hrs}$ during the period. Maximum wind speed occurs around midnight on 21st August and in early morning/late evening on other days, while a minimum occurs around noon/afternoon during the observation period. Cloud amount was maximum around afternoon/evening hours, while it was minimum around midnight/early morning.

Figure 1(a) shows the diurnal and synoptic scale variation of SST (daily mean value indicated at noon of the day). It is observed that the SST shows a smooth synoptic scale variation by $0.2^{\circ} \mathrm{C}$ during the period. Variation of the order of one degree in SST is seen during intensification of the system (18th - 19th August) into a depression. Mean SST decreases smoothly during 18th-22nd August and then rises during 23rd - 25th August. Figure 1(b) shows the pressure variation during the period. Pressure is minimum on the evening of 20th August showing the formation of depression, and then rises sharply up to 23rd August showing diurnal oscillations thenceforth. Wind speed in figure 1(c) increases sharply during 18th - 21st August, correlating with the presssure drop, and then falls rapidly after 21 st - 22nd August. The cloud amount in figure 1 (d) shows a nearly overcast sky on 20 th -21 st August. It shows an oscillation between 4 and 6 octas at other times. 


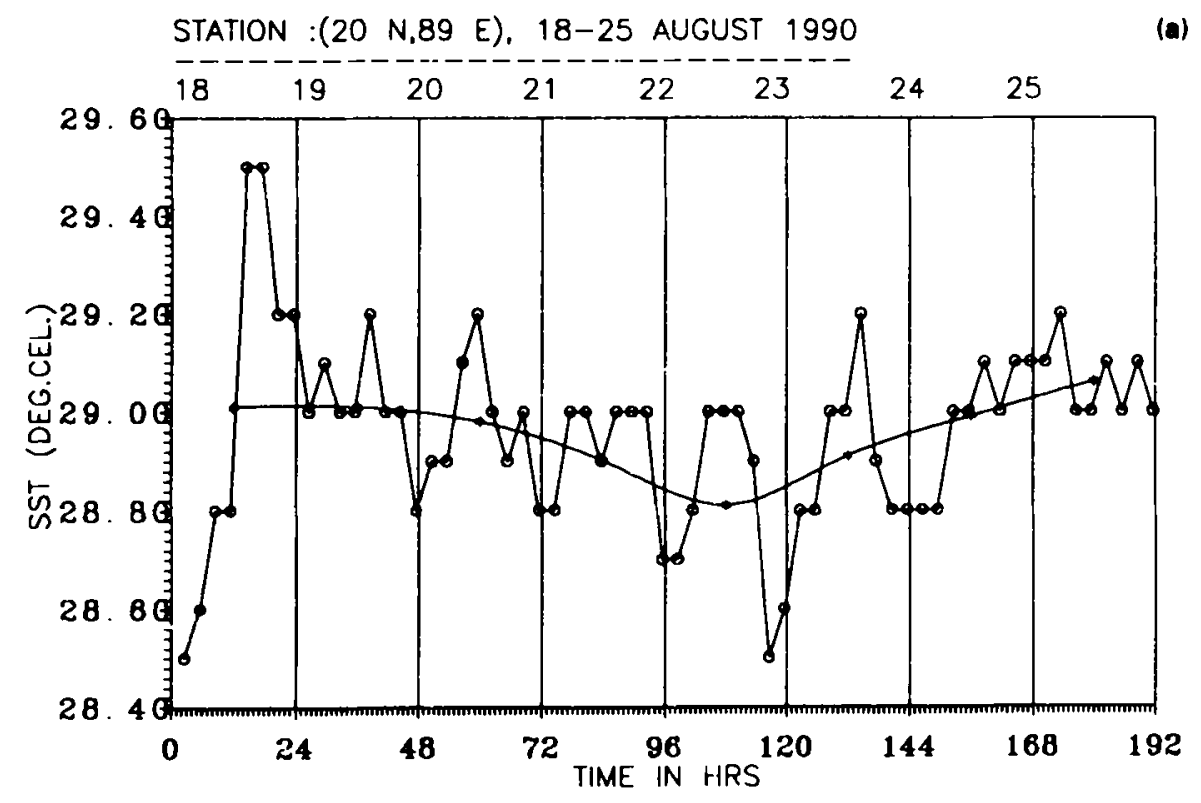

Figure 1(a). Time variation of sea surface temperature cver the Bay of Bengal station during 18th - 25th August, 1990.

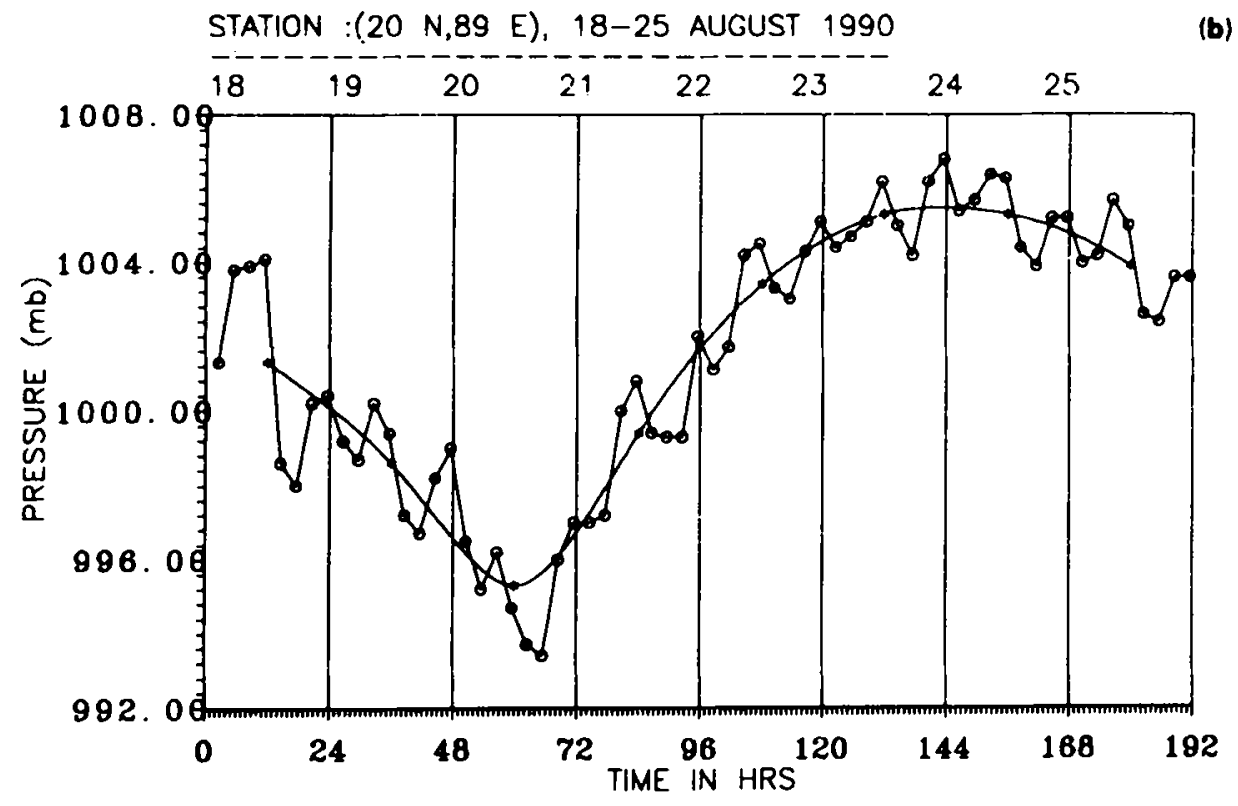

Figure 1(b). Same as in figure 1(a) for pressure. 


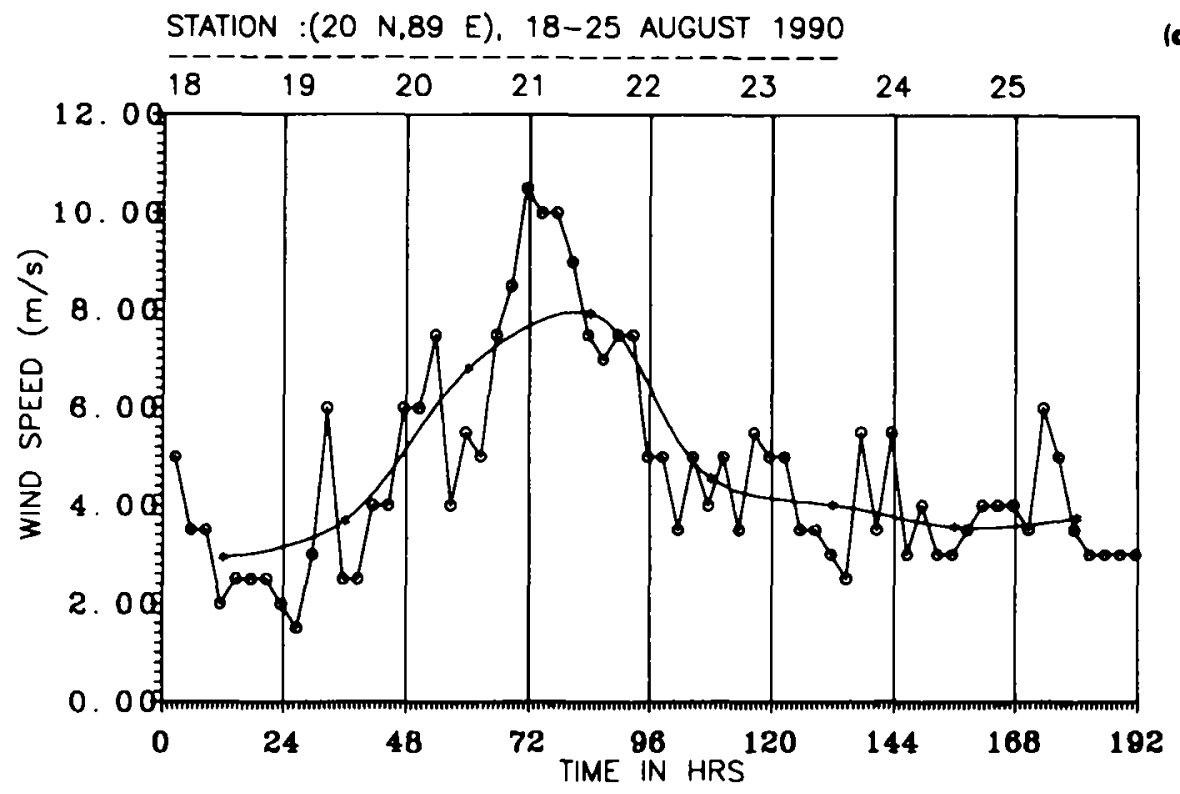

Figure 1(c). Same as in figure 1(a) for wind speed.

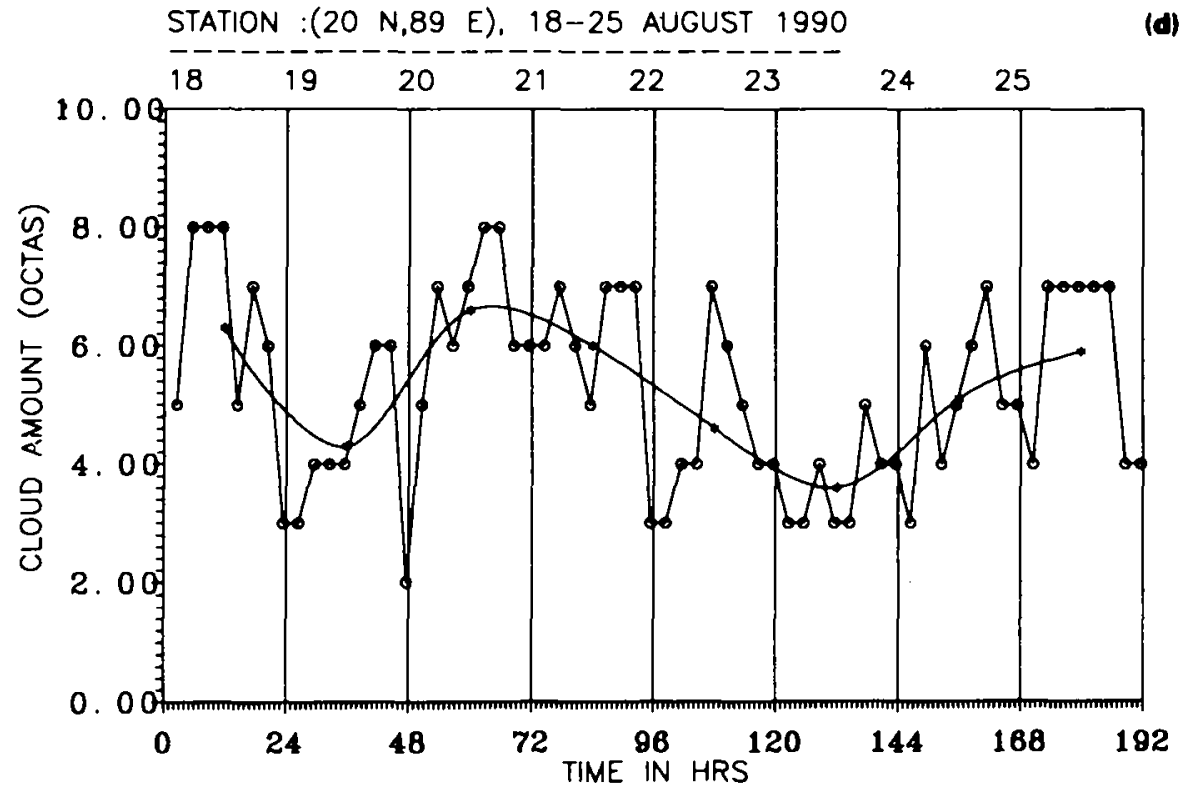

Figure 1(d). Same as in figure 1 (a) for cloud amount. 


\subsection{Surface fluxes}

Fiuxes of sensible and latent heat, water vapour and momentum are shown in figure 2(a)-(d) respectively for the period (August $18 \mathrm{th}-25 \mathrm{th}$ ). It is seen that the time variation of fluxes is nearly in phase. The fluxes of sensible and latent heat, water vapour and momentum were maximum during late evening to midnight and were minimum around noon.

All these fluxes depict a maximum around midnight of August 21st, when wind speeds are high $(10 \mathrm{~m} / \mathrm{s})$. In figure $2(\mathrm{a})$-(d) the fluxes show diurnal variations such that they increase consistently around midnight to early morning hours and decrease around noon or afternoon. Interestingly we observe a diurnal variation of fluxes over this sea station, which is about 150 miles away from the nearest coastal station (Paradeep). Daily mean variation of the fluxes (marked in figure at noon of the day) of sensible and latent heat and water vapour shows a sharp increase from August 19th, attaining a maximum on $20 \mathrm{th}-21$ st, then falling on $22 \mathrm{nd}-23 \mathrm{rd}$, and remaining nearly constant thereafter. The momentum flux shows a steep rise from 18th August reaching maximum on 21st August, and then falls sharply on 22nd-23rd, remaining nearly constant thenceforth. In contrast to the normal feature over land, the fluxes over sea show a minimum around noon/afternoon hours during the entire period. Around $0830-1130 \mathrm{hrs}$, we observe that the stability of the surface layer as determined by $Z / L$ $(Z=9 \mathrm{~m})$ tends towards near neutral conditions. The condition on the whole (18th25th August) is unstable during day and night; transitions to slightly stable conditions are seen in day time around $0830-1430 \mathrm{hrs}$ IST. Night time instability is due to the sea surface being warmer than the air above. Figure 3 shows the time variation of Bowen ratio.

\subsection{Energy exchange coefficients}

The exchange coefficients, the heat exchange coefficient or Stanton number $\left(C_{H}\right)$, the drag coefficient $\left(C_{D}\right)$ and the moisture exchange coefficient or Dalton number $\left(C_{E}\right)$ have been estimated from the mean daily fluxes of sensible heat, momentum and latent heat computed by the profile method. The mean $C_{H}, C_{D}$ and $C_{E}$ are estimated as $7.65 \times 10^{-3}, 3.72 \times 10^{-3}$ and $5.64 \times 10^{-3}$ respectively during convective conditions. When these estimated mean exchange coefficients were used in the bulk aerodynamic method, it was found that the estimated heat fluxes nearly agree within $10-20 \%$ by both methods during 20 th -25 th August and differ by more than $40 \%$ on 18 th and 19th August. The momentum flux by the bulk method is less by a factor of 1.2-1.4 compared to the profile method value during $20 \mathrm{th}-25 \mathrm{th}$ August, and by a factor of 1.4 and 1.6 on 18 th and 19th August respectively.

\subsection{Comparison of fluxes estimated by profile and bulk aerodynamic method}

For the period under study, the daily mean fluxes of sensible and latent heat and momentum were estimated independently by Singh (1992) using the bulk aerodynamic method on the assumption that $C_{D}=C_{H}=C_{E}$ (Bunker 1976). These fluxes are compared with those estimated by the profile method and are shown in table 1.

The fluxes estimated by Singh (1992) using the bulk aerodynamic method are less in magnitude by a factor of about $4-10$ for sensible heat, and 1.7-2.5 for latent heat, than 


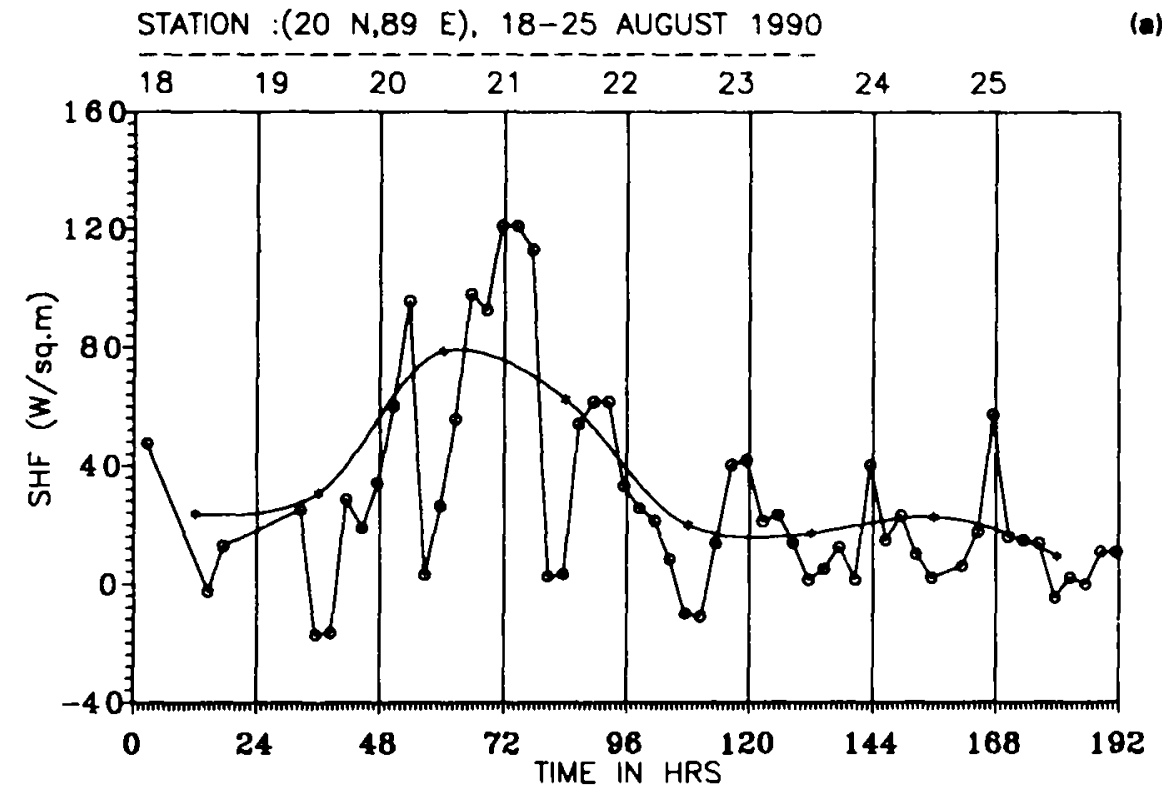

Figure 2(a). Time variation of sensible heat flux during 18th - 25 th August, 1990.

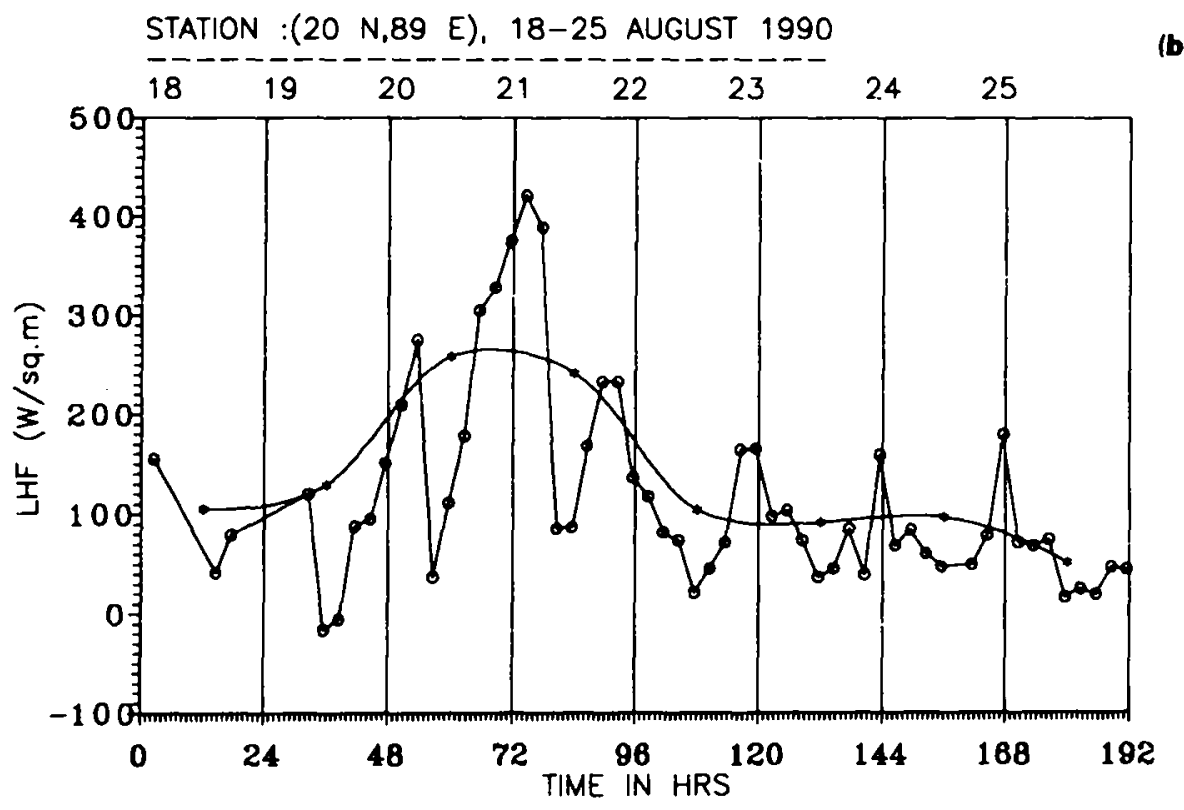

Figure 2(b). Same as in figure 2(a) for latent heat flux. 


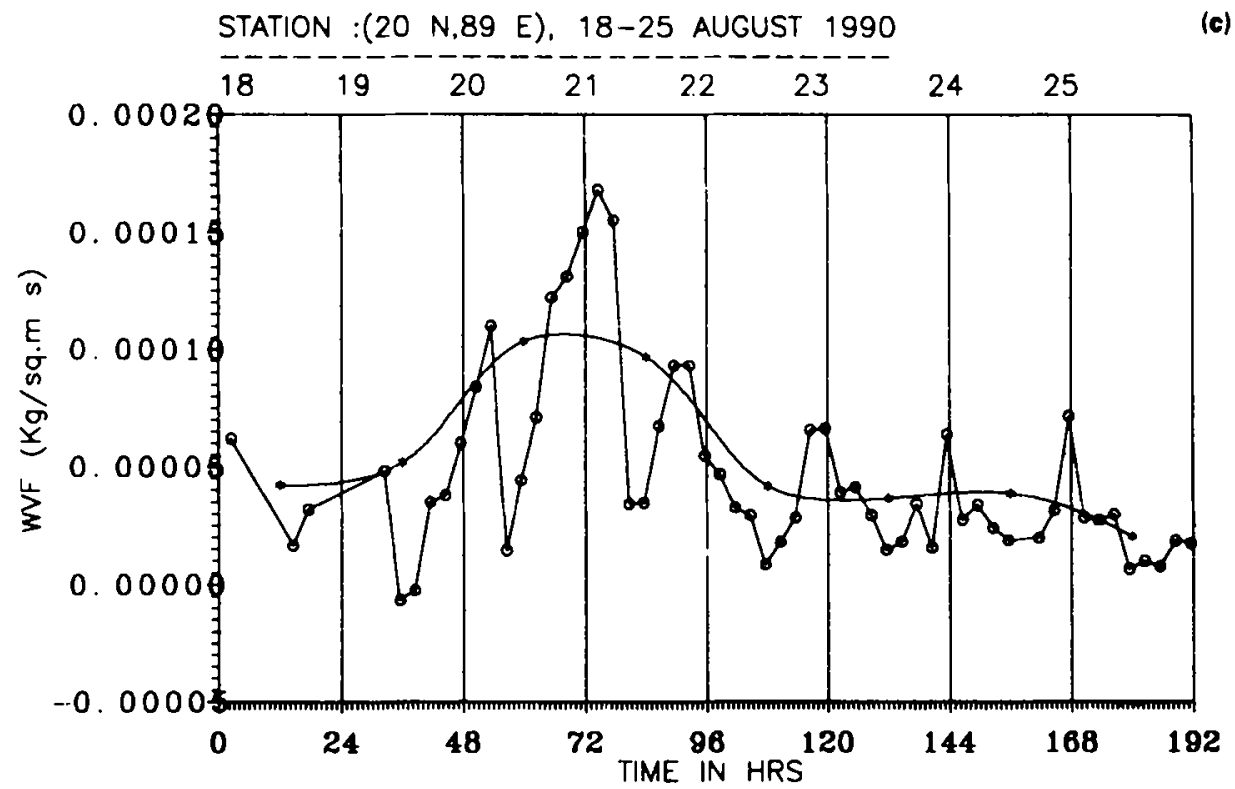

Figure 2(c). Same as in figure 2(a) for water vapour flux.

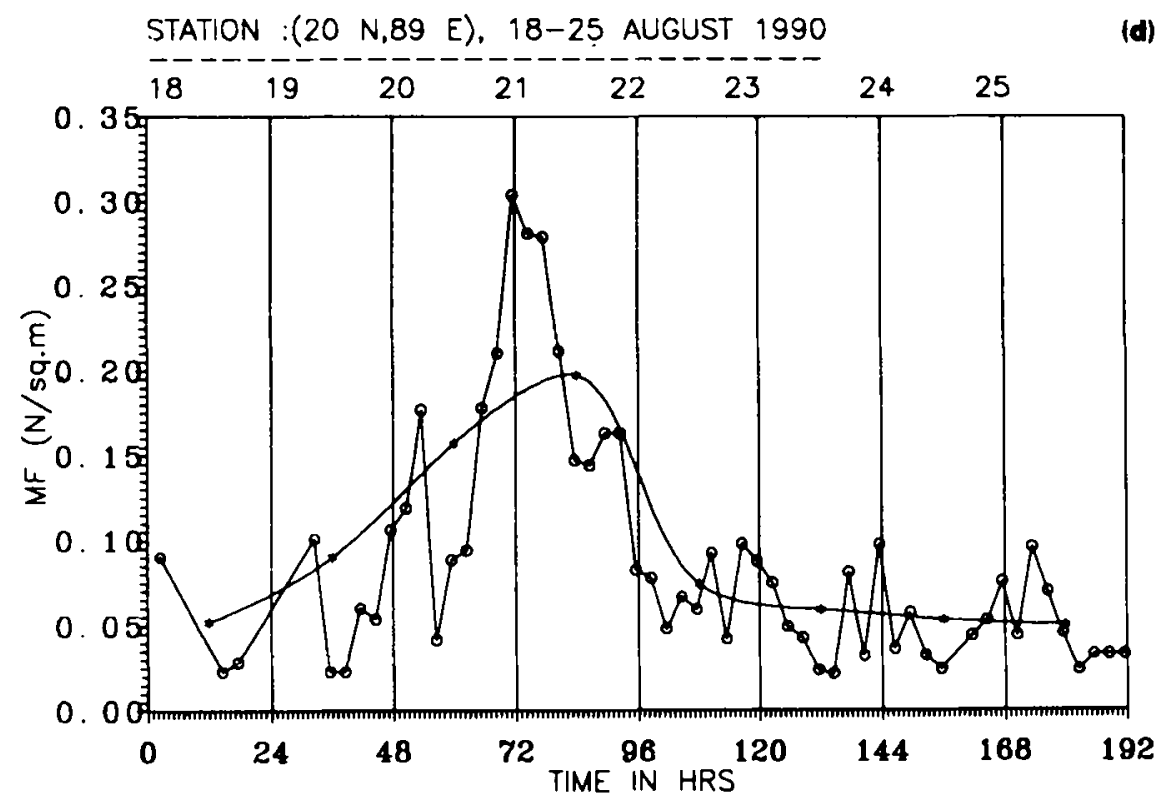

Figure 2(d). Same as in figure 2(a) for momentum flux. 


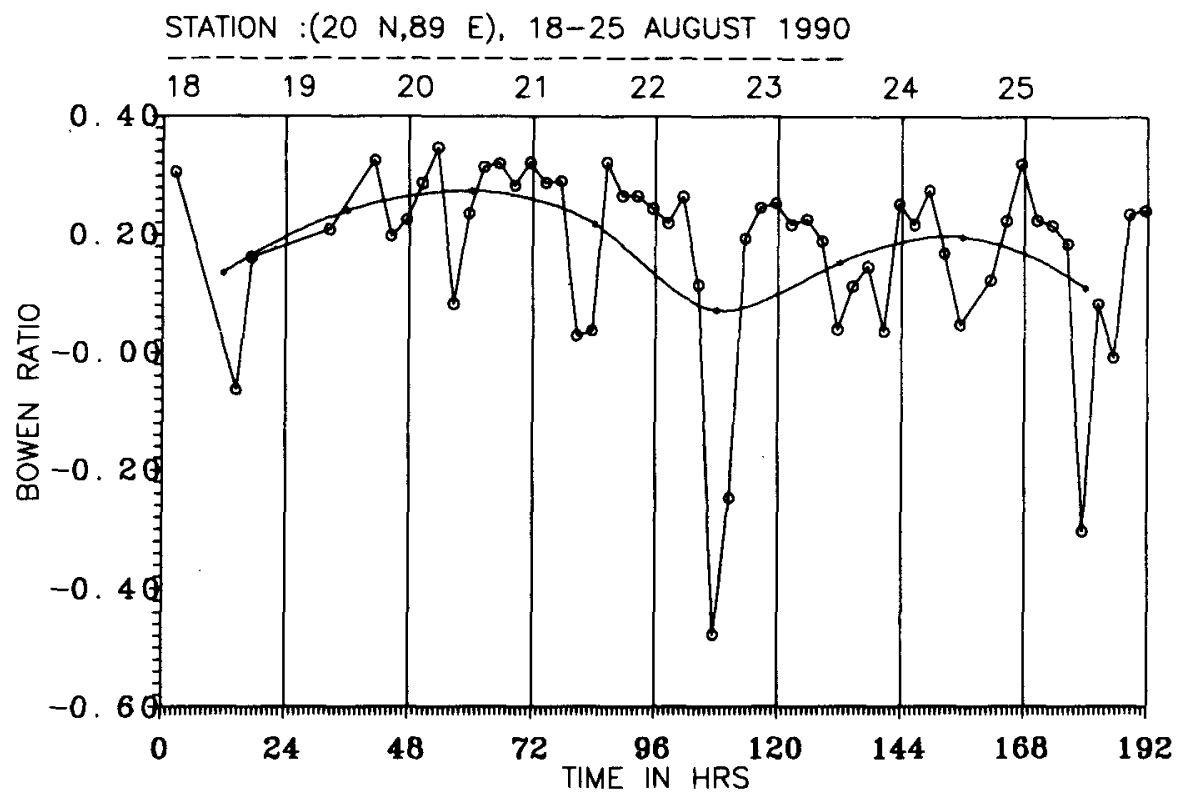

Figure 3. Time variation of Bowen ratio during 18th - 25th August, 1990.

Table 1. Comparison of daily average value of fluxes over Bay of Bengal $\left(20^{\circ} \mathrm{N}, 89^{\circ} \mathrm{E}\right)$ during August 18 th -25 th, 1990 , by profile $(\mathrm{P})$ and bulk aerodynamic (B) method.

\begin{tabular}{|c|c|c|c|c|c|c|}
\hline \multirow{2}{*}{$\begin{array}{l}\text { Day } \\
\text { August } \\
1990\end{array}$} & \multicolumn{2}{|c|}{$\begin{array}{l}\text { Sensible heat } \\
\text { flux }\left(W / m^{2}\right)\end{array}$} & \multicolumn{2}{|c|}{$\begin{array}{l}\text { Latent heat } \\
\text { flux }\left(W / \mathrm{m}^{2}\right)\end{array}$} & \multicolumn{2}{|c|}{$\begin{array}{l}\text { Momentum flux } \\
\left(\mathrm{N} / \mathrm{m}^{2}\right)\end{array}$} \\
\hline & $\mathbf{P}$ & B & $\mathbf{P}$ & B & $\mathbf{P}$ & B \\
\hline 18 & $23 \cdot 6$ & $5 \cdot 5$ & $105 \cdot 3$ & $42 \cdot 0$ & 0.052 & 0.007 \\
\hline 19 & $30 \cdot 6$ & 3.0 & $129 \cdot 3$ & 61.0 & 0.090 & 0.030 \\
\hline 20 & $78 \cdot 6$ & $16 \cdot 0$ & $258 \cdot 1$ & $109 \cdot 0$ & 0.157 & 0.093 \\
\hline 21 & $62 \cdot 4$ & $9 \cdot 0$ & $241 \cdot 3$ & $116 \cdot 0$ & 0.197 & 0.088 \\
\hline 22 & $19 \cdot 9$ & $3 \cdot 0$ & $104 \cdot 1$ & 65.6 & 0.074 & 0.035 \\
\hline 23 & $17 \cdot 1$ & $2 \cdot 0$ & $91 \cdot 2$ & $50 \cdot 0$ & 0.059 & 0.025 \\
\hline 24 & $22 \cdot 6$ & $3 \cdot 5$ & $112 \cdot 7$ & $48 \cdot 0$ & 0.053 & 0.020 \\
\hline 25 & $9 \cdot 2$ & $2 \cdot 0$ & $50 \cdot 6$ & $30 \cdot 0$ & 0.050 & 0.030 \\
\hline
\end{tabular}

those estimated by the profile method. A detailed study on $C_{D}$ over the north Bay of Bengal $\left(20^{\circ} \mathrm{N}, 89^{\circ} \mathrm{E}\right)$ can be found in Patil and Sivaramakrishnan (1994), which shows that $C_{D}$ is a strong function of stability, increasing with increasing instability; the $C_{D}$ under neutral stability $\left(C_{D N}\right)$ was found to be $1.45 \times 10^{-3}$. When we used this $C_{D N}$ in the computation of momentum flux by the bulk aerodynamic method, we found that its magnitude agrees well with that estimated by Singh (1992). The momentum flux in table 1 calculated by the profile method is higher by a factor of $1.5-3$ during 19 th -25 th August. Values of fluxes in table 1 clearly imply that the equality $C_{D}=C_{H}=C_{E}$ is not appropriate in disturbed weather (depression) conditions. The ratio of $C_{H}$ and $C_{E}$ to $C_{D}$ is found to be 2.05 and 1.51 respectively and that of $C_{H}$ to $C_{E}$ is 1.36 . 


\section{Conclusions}

- The fluxes of sensible and latent heat, water vapour and momentum over sea show diurnal and synoptic scale variations due to variability of the weather disturbance near the station.

- The fluxes increase during the depression period and show systematic diurnal trend afterwards.

- Under unstable conditions (disturbance) the assumption $C_{D}=C_{H}=C_{E}$ is not appropriate.

\section{Acknowledgements}

The authors are thankful to the Director, Indian Institute of Tropical Meteorology, Pune, for his interest and encouragement and DST for providing the data collected by NIO, Goa, during MONTBLEX-90.

\section{References}

Berkowicz R and Prahm L R 1982 Evaluation of the profile method for estimation of surface fluxes of momentum and heat, Atmos. Environ. 16 2809-2819

Binkowski F S 1975 On the empirical relationship between the Richardson number and the MoninObukhov stability parameter; Atmos. Environ. 9 453-454

Blanc T V 1982, Profile-bulk method formulas for calculating flux and stability in the marine atmospheric surface layer and a survey of field experiments, NRL Report 8647

Bunker A F 1976 Computations of surface energy flux and annual air-sea interaction cycle of the North Atlantic Ocean, Mon. Weather Rev. 104 1122-1139

Businger J A, Wyngaard J C, Izumi Y and Bradley E F 1971 Flux-profile relationship in the atmospheric surface layer; J. Atmos. Sci. 28 181-189

Counihan J 1975 Adiabatic atmospheric boundary layers: A review and analysis of data from the period 1880-1972, Atmos. Environ. $9871-905$

Louis J F 1979 A parametric model of the vertical eddy fluxes in the atmosphere; Boundary-Layer Meteorol. 17, 187-202

Oceanographic and Meteorological data - (ORV Sagarkanya) Cruise: 56; MONTBLEX-90, NIO, Goa, Nov. 1990

Patil M N and Sivaramakrishnan S 1994 Variation of drag coefficient with stability over sea, 8th National Space Science Symposium held at SPL, VSSC, Trivandrum, MT-45, 101-102

Singh O P 1992 Surface fluxes and the cyclogenesis over north and adjoining central Bay of Bengal during MONTBLEX-1990, Mausam, 43 399-402 